06

\title{
Фемтосекундное многофотонное возбуждение люминесценции примесных ионов в кристаллах
}

\author{
(С) В.И. Барышников ${ }^{1,2}$, О.В. Горева ${ }^{1}$, Ю.А. Григорьева ${ }^{1}$, О.Л. Никонович ${ }^{1}$ \\ ${ }^{1}$ Иркутский государственный университет путей сообщения, \\ 664074 Иркутск, Россия \\ ${ }^{2}$ Иркутский фрилиал Института лазерной фризики Сибирского отделения РАН, \\ 664033 Иркутск Россия \\ e-mail: vibh@rambler.ru
}

Поступила в редакцию 03.08.2018 г.

В окончательной редакции 08.10.2018 г.

Принята к публикации 06.11.2018 г.

Исследован механизм возбуждения люминесценции примесного состава в кристаллических материалах под действием интенсивного фемтосекундного лазерного излучения. Установлено, что в ходе фемтосекундной трехфотонной ионизации собственного вещества кристалла образуется высокая концентрации зонных электронов и дырок, которые последовательно захватываются примесными ионами. Эффективность электронно-дырочного возбуждения примесного состава в кристаллах, как и при воздействии электронным пучком, определяется степенью различия электронных систем $s$-, $p$-, $d$-подгрупп внешней оболочки катионов собственного вещества и активатора.

DOI: $10.21883 /$ OS.2019.03.47375.230-18

\section{Введение}

Кардинальное увеличение объемной плотности мощности источников фемтосекундного лазерного излучения обеспечивает высокий темп возбуждения кристаллического вещества диэлектриков, при котором происходит эффективная многофотонная ионизация собственных ионов и наводятся электроны зоны проводимости и дырки валентной зоны $[1,2]$. На основе данных особенностей лазерного возбуждения кристаллов значительное развитие получили исследования фундаментального и прикладного характера. Прежде всего, это определение быстропротекающих механизмов взаимодействия мощного фемтосекундного лазерного излучения с веществом и углубление фундаментальных основ высокоэнергетической физики твердого тела $[3,4]$. Разработка новых систем и элементов квантовой электронной техники, методов и аппаратуры эффективной диагностики диэлектрических материалов [5-7].

Известно [8-10], что в кристаллах, возбуждаемых сильноточными наносекундными электронными пучками, достигается высокий темп возбуждения вещества, при котором на временном интервале $0.1-10 \mathrm{~ns}$ происходит передача интенсивного ударного воздействия и лавинно наводится высокая концентрация зонных электронов и дырок $\left(10^{19}-10^{21} \mathrm{~cm}^{-3}\right)$. При этом установлено, что в ионных кристаллах выход наносекундной катодолюминесценции (КЛ) примесных ионов определяется эффективностью их взаимодействия с наведенными зонными носителями заряда, которое зависит от степени различия электронных систем $s-, p-, d$-подгрупп внешней оболочки ионов собственного вещества и активатора. То есть при различии валентных электронных структур ионов активатора и собственного вещества, потенциал в окрестности примесных ионов, сформированный $s$ , $p$-, $d$-подгруппами валентных электронных оболочек, нерегулярен. В этом случае принцип Блоха нарушается, и зонные электроны $(e)$ и дырки $(h)$ в процессе миграции эффективно передают энергию примесным дефектам [8,9]. Так, например, в кристаллах $\mathrm{Ce}: \mathrm{YAlO}_{3}$; $\mathrm{Ce}: \mathrm{Y}_{3} \mathrm{Al}_{5} \mathrm{O}_{12} ; \mathrm{Ti}: \mathrm{Al}_{2} \mathrm{O}_{3} ; \mathrm{Er}: \mathrm{BaY}_{2} \mathrm{~F}_{8} ; \mathrm{Tl}: \mathrm{NaI}$ и др. наблюдается высокий выход примесной КЛ ( 10\%) при незначительной концентрации активатора в веществе (0.1 wt.\%).

По данным [1-3], в ходе фемтосекундного многофотонного лазерного и сильноточного наносекундного электронного возбуждения ионных кристаллов достигается значительная по величине, наведенная в ходе ионизации собственного вещества, концентрация зонных носителей заряда. Вместе с тем в течение фемтосекундного лазерного воздействия при длительности импульса, например $5 \cdot 10^{-14} \mathrm{~s}$, можно считать, что наведенные зонные электроны и дырки неподвижны. И напротив, в ходе воздействия импульса наносекундного электронного пучка, который по длительности на 3-4 порядка более продолжителен, эффективность возбуждения люминесценции легирующей примеси зависит не только от степени различия электронных систем $s-, p$-, $d$-подгрупп внешней оболочки ионов собственного вещества и активатора, но и определяется временем миграции наведенных зонных электронов и дырок [8,9]. Такие особенности в механизмах лазерного фемтосекундного возбуждения легирующей примеси с участием наведенных зонных электронов и дырок при многофотонной ионизации собственного вещества в диэлектрических кристаллах не изучены. Таким образом, целью работы является изуче- 
ние механизмов мультифотонного фемтосекундного возбуждения фотолюминесценции (ФЛ) примесных ионов в диэлектрических кристаллах на фемтосекундных и наносекундных временных интервалах.

\section{Образцы, методы и техника исследования}

В экспериментах исследовались полированные со всех сторон легированные, номинальной и высокой чистоты кристаллы $\mathrm{YAlO}_{3}, \mathrm{Y}_{3} \mathrm{Al}_{5} \mathrm{O}_{12}, \mathrm{Al}_{2} \mathrm{O}_{3}, \mathrm{Y}_{2} \mathrm{SiO}_{5}, \mathrm{LiLuF}_{4}$, $\mathrm{BeAl}_{2} \mathrm{O}_{4}, \mathrm{YAlO}_{3}, \mathrm{LaF}_{3}, \mathrm{NaCl}$ и др. $\left(20 \times 5 \times 5 \mathrm{~mm}^{3}\right)$. Для возбуждения ФЛ примесей в режиме многофотонного возбуждения использовалась вторая гармоника фемтосекундного перестраиваемого $\mathrm{Ti}_{\mathrm{i}} \mathrm{Al}_{2} \mathrm{O}_{3}$ лазера TIF-50. Регулировка длительности фемтосекундных импульсов производилась в диапазоне 50-100 fs. Фемтосекундные лазерные импульсы посредством юстировочной системы подавались на торцевую поверхность кристалла. Прецизионная система юстировки широкополосного сферического зеркала и продольного перемещения исследуемого кристалла обеспечивала плавную регулировку интенсивности в кристалле лазерного фемтосекундного пучка, вплоть до области гауссовой перетяжки. Импульсная интенсивность лазерного излучения в области гауссовой перетяжки достигает $2.5 \mathrm{GW} / \mathrm{cm}^{2}$. Зеркала изготовлены методом напыления алюминия на соответствующие стеклянные подложки.

Для возбуждения КЛ использован коаксиально сочлененный с вакуумным криостатом миниатюрный наносекундный сильноточный ускоритель электронов с энергией электронов в пучке $250 \mathrm{keV}$, плотностью тока $0.1-2.0 \mathrm{kA} / \mathrm{cm}^{2}$ и длительностью импульса $1 \mathrm{~ns}$. Через кварцевые окна вакуумного малоиндуктивного криостата на образец направлялось излучение фемтосекундного лазера и велось измерение спектрально кинетических параметров КЛ и ФЛ.

Контроль спектральных и временных параметров фемтосекундных лазерных импульсов производился соответственно с помощью спектрометра ASP-100M и автокоррелятора на основе прецизионного интерферометра Майкельсона. Управление работой спектрометра и интерферометра производилось посредством специального программного обеспечения.

Регистрация пространственного распределения спектральной интенсивности фотолюминесценции в кристалле производилась системой, в составе которой спектрограф МДР-4, стробируемый с наносекундным разрешением микроканальный электронно-оптический преобразователь (ЭОП), импульсная ПЗС-матрица с объективом и модулем микропроцессорного управления, контроля и передачей данных. Выбор оптимальной чувствительности импульсной ЭОП-ПЗС системы обеспечивается специальным программным обеспечением. Следует отметить, что импульсный метод регистрации спектрального

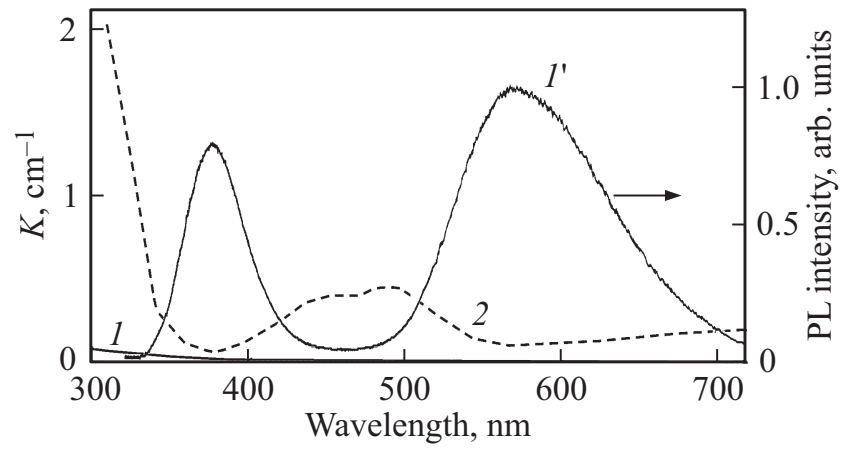

Рис. 1. Спектры поглощения $(1,2)$ номинально чистого (содержание Се и Тi около $10^{-4}$ wt.\%) (1) и легированного $\left(10^{-1}\right.$ wt.\% Ti) (2) кристалла $\mathrm{YAlO}_{3}$, спектр одноимпульсной ФЛ $\mathrm{Ti}^{3+}$ и $\mathrm{Ce}^{3+}\left(1^{\prime}\right)$ при $300 \mathrm{~K}$. Возбуждение: $2 \omega: \mathrm{Ti}: \dot{\mathrm{Sp}}$ лазер, $\lambda=390 \mathrm{~nm}$. Регистрация: задержка $5 \mathrm{~ns}$, экспозиция $10 \mu \mathrm{s}$.

распределения интенсивности ФЛ и КЛ примесей в канале лазерного возбуждения даже при микросекундных экспозициях позволяет устранить внешние оптические шумы.

Импульсный фототок в кристаллах измерялся в специальной коаксиальной малоиндуктивной кювете при помощи осциллографа Tektronix TDS3032B. Титановые электроды размером $2.0 \times 2.0 \mathrm{~mm}^{2}$ прижимались к кристаллу толщиной $2.0 \mathrm{~mm}$ через индий-галлиевую эвтектику и токосъем производился на коаксиальный разъем. Коаксиальный кабель-накопитель импульсно заряжался до напряжения $5 \mathrm{kV}$ и разряжался через образец на нагрузку $50 \Omega$. Лазерный пучок диаметром $1 \mathrm{~mm}$ подавался на кристалл через вышеуказанную юстировочную систему перпендикулярно к линиям напряженности электрического поля. Эта серия экспериментов проводилась на полированных образцах в виде пластин $8 \times 8 \times 1 \mathrm{~mm}^{3}$. Временное разрешение кювета-осциллограф соответствует $1 \mathrm{~ns}$.

\section{Фемтосекундное лазерное возбуждение в кристаллах примесных ионов и наведенная фотопроводимость}

В ходе возбуждения номинально чистых кристаллов $\mathrm{YAlO}_{3}$ (содержание $\mathrm{Ce}$ и $\mathrm{Ti}$ около $10^{-4} \mathrm{wt} . \%$ ) перестраиваемым излучением $2 \omega: \mathrm{Ti}: \mathrm{Sp}$-лазера $(390 \mathrm{~nm}$, $80 \mathrm{MHz}, 50 \mathrm{fs}$ ) обнаружены две полосы люминесценции при 380 и $575 \mathrm{~nm}$ (рис. 1), которые идентифицированы по методу [11] и связаны соответственно с излучением примеси $\mathrm{Ce}^{3+}$ и $\mathrm{Ti}^{3+}$. Установлено, что при фемтосекундном возбуждении на длине волны $\lambda_{\mathrm{B}}=480 \mathrm{~nm}\left(3 h v=7.8 \mathrm{eV} \approx E_{g}=7.8 \mathrm{eV}\right)$ указанная ФЛ не наблюдается, а при возбуждении на $\lambda_{\mathrm{B}}=470 \mathrm{~nm}\left(3 h v=7.9 \mathrm{eV}>E_{g}\right)$ появляется и до $\lambda_{\mathrm{B}}=450 \mathrm{~nm}\left(3 h v=8.3 \mathrm{eV}>E_{g}\right)$ ее интенсивность существенно возрастает. Кроме того, выход ФЛ $\mathrm{Ce}^{3+}$ и $\mathrm{Ti}^{3+}$ 


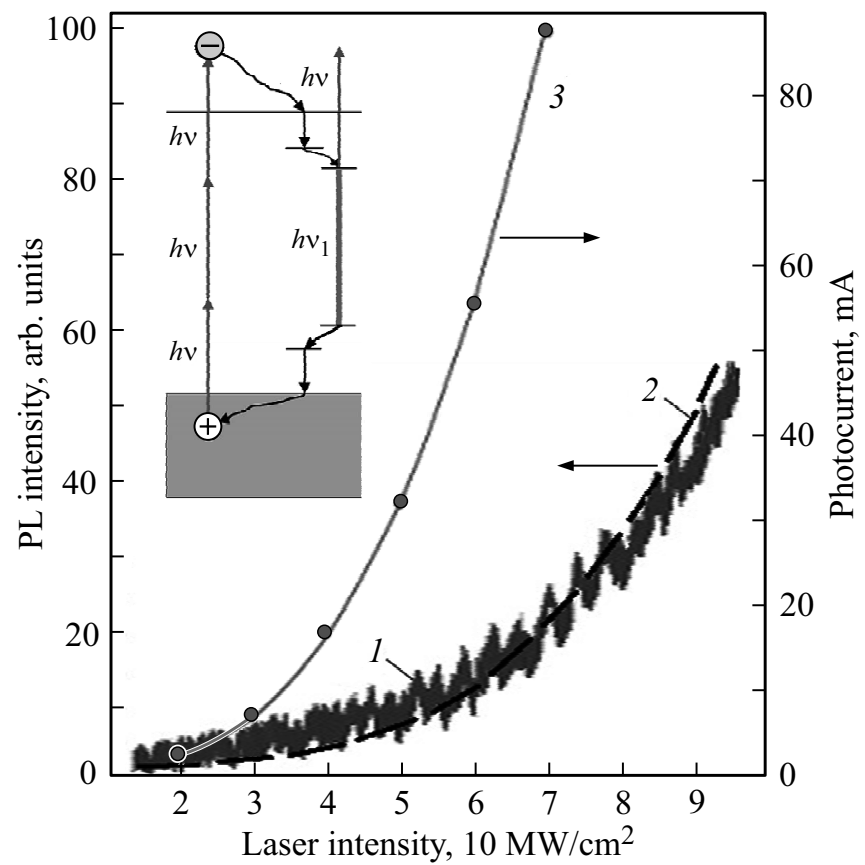

Рис. 2. Зависимость интенсивности ФЛ $(1,2)$ примесных ионов $\mathrm{Ce}^{3+}$ и импульсного фототока (3) в кристаллах $\mathrm{YAlO}_{3}$ при $300 \mathrm{~K}$ от плотности мощности фемтосекундного лазерного возбуждения, $\lambda=390 \mathrm{~nm}: 1$ - эксперимент, 2 - компьютерное моделирование. На вставке: квантовая система и электронные переходы при трехфотонном возбуждении ФЛ ионов $\mathrm{Ce}^{3+}$.

имеет нелинейную зависимость от интенсивности фемтосекундного лазерного воздействия (рис. 2) и практически не зависит от температуры в интервале 78-300 К. Полученные результаты указывают на трехфотонный механизм возбуждения ионов $\mathrm{Ce}^{3+}$ и $\mathrm{Ti}^{3+}$ в кристаллах $\mathrm{YAlO}_{3}$ и позволяют считать, что процесс возбуждения ФЛ $\mathrm{Ce}^{3+}$ и $\mathrm{Ti}^{3+}$ происходит путем последовательного захвата зонных дырок и электронов по реакции (1), которые наводятся по механизму трехфотонной ионизации собственного вещества кристаллов:

$$
\begin{gathered}
3 h v \rightarrow R\left(\mathrm{O}^{2-}\right) \rightarrow e+h \\
\left\langle\begin{array}{c}
\mathrm{Ti}^{3+}+h \rightarrow \mathrm{Ti}^{4+}+e \rightarrow\left(\mathrm{Ti}^{3+}\right)^{*} \rightarrow \mathrm{Ti}^{3+}+h v_{\mathrm{Ti}^{3+}} \\
\mathrm{Ce}^{3+}+h \rightarrow \mathrm{Ce}^{4+}+e \rightarrow\left(\mathrm{Ce}^{3+}\right)^{*} \rightarrow \mathrm{Ce}^{3+}+h v_{\mathrm{Ce}^{3+}}
\end{array}\right\rangle .
\end{gathered}
$$

Для проверки данного утверждения была измерена зависимость импульсной фотопроводимости кристалла $\mathrm{YAlO}_{3}$ от интенсивности фемтосекундного лазерного возбуждения на длине волны $390 \mathrm{~nm}$. При этом использовались кристаллы номинальной частоты (примесей $10^{-4}$ wt. $\left.\%\right)$.

Кристалл в соответствии со схемой эксперимента устанавливался так, что лазерный пучок полностью перерывал торцевую площадь кристалла. Величина импульсного тока фотопроводимости имеет кубическую зависимость от интенсивности фемтосекундного лазерного возбуждения $\mathrm{YAlO}_{3}$ кристалла (рис. 2). Зависи- мость импульсного тока фотопроводимости от интенсивности фемтосекундного лазерного возбуждения на длине $360 \mathrm{~nm}$ имеет близкую кубическую закономерность для кристаллов $\mathrm{Y}_{3} \mathrm{Al}_{5} \mathrm{O}_{12}, \mathrm{Al}_{2} \mathrm{O}_{3}, \mathrm{LaF}_{3}, \mathrm{NaCl}$. Таким образом, в указанных кристаллах, как и в $\mathrm{YAlO}_{3}$, примесные дефекты могут возбуждаться путем последовательного взаимодействия с наведенными зонными электронами и дырками в результате трехфотонной ионизации собственного вещества кристалла.

Анализ зависимости величины импульсного фототока и интенсивности люминесценции примесных центров от плотности мощности фемтосекундных лазерных импульсов показывает их принципиальное различие (рис. 2). Так, в соответствии с механизмом трехфотонной ионизации собственного вещества кристалла величина импульсного тока фотопроводимости имеет кубическую зависимость от интенсивности фемтосекундного лазерного возбуждения, а выход примесной ФЛ - квадратичную (рис. 2). Данное различие зависимостей тока проводимости и выхода люминесценции примесей от объемной плотности фемтосекундного лазерного возбуждения кристаллов обусловлено тем, что концентрация наведенных электронов в зоне проводимости соответствует выражению

$$
n_{e}=\frac{\gamma I^{3}}{3 h v}=\frac{j n}{c e},
$$

где $I$ - интенсивность фемтосекундных лазерных импульсов, $\gamma=\mathrm{cm}^{3} \cdot \mathrm{s} \cdot \mathrm{W}^{-2}-$ коэффициент трехфотонного поглощения, $h v-$ энергия фотона, $j-$ плотность тока фотопроводимости, $e-$ заряд электрона, $n-$ показатель преломления кристалла, $c$ - скорость света.

Известно, что процесс возбуждения примесных ионов, наведенными зонными электронами и дырками, состоит из этапов миграции и захвата, когда электрон достигает сферу действия примеси и передает энергию в соответствии с сечением взаимодействия $[8,12]$. Отсюда время возбуждения примеси составляет $t_{r}+t_{c}$, где $t_{r}$ - время миграции, $t_{c}$ - время захвата ионом электрона или дырки примесью. Поскольку $t_{r} \gg t_{c}$, то время возбуждения примеси практически определяется временем $t_{r}$. В течение времени $t_{r}=10^{-11} \mathrm{~s}$ и электрон, и дырка в процессе миграции могут попасть в поле действия примесного иона, пройдя дистанцию более 100 регулярных узлов кристаллической решетки $[8,12]$. Зонные носители заряда, не попавшие в поле действия примесного иона, в ходе миграционного процесса теряют кинетическую энергию и спустя время $t_{r}$ достигают соответственно дна зоны проводимости и потолка валентной зоны (рис. 2), переходя в малоподвижное (термализованное) состояние с временем жизни $t_{t}=10^{-9} \mathrm{~s}[10]$. Эффективность процесса захвата примесными ионами термализованных носителей заряда на временном интервале от $10^{-11} \mathrm{~s}$ до $10^{-9} \mathrm{~s}$ на два порядка ниже, чем в ходе их миграционного процесса $[8,12]$. Тогда при условии 
$t_{r}=10^{-11} \mathrm{~s} \gg t_{\mathrm{exc}}=5 \cdot 10^{-14} \mathrm{~s}$ концентрация возбужденных примесных ионов после первого фемтосекундного лазерного импульса определяется по формуле

$$
N_{a}^{*}=\frac{\gamma I^{3}}{3 h v} \sigma_{a} N_{a} t_{r}
$$

где $N_{a}$ - концентрация примеси в кристалле, $\sigma_{a}-$ сечение взаимодействия зонных носителей заряда с примесными ионами. На последующих импульсах фемтосекундного лазерного возбуждения с периодом следования $T_{\mathrm{exc}}=1.2 \cdot 10^{-8} \mathrm{~s}$ при времени жизни в возбужденном состоянии примесных ионов $\tau$ от $2.5 \cdot 10^{-8}$ до $11 \cdot 10^{-6}$ s справедливо выражение

$$
N_{a_{m+1}}^{*}=\frac{\gamma I^{3}}{3 h v} \sigma_{a} N_{a} t_{r}-\alpha N_{a_{m}}^{*} I t_{\mathrm{exc}}
$$

где $\alpha-$ коэффициент поглощения из возбужденного состояния примесного иона (рис. 2), $t_{\mathrm{exc}}$ - длительность фемтосекундного импульса. Близкие к квадратичной зависимости выход ФЛ примесей от интенсивности фемтосекундного лазерного возбуждения, полученный в эксперименте и путем компьютерного моделирования формулы (4) по параметрам эксперимента для $\mathrm{Ce}^{3+}$ в кристаллах $\mathrm{YAlO}_{3}$, практически совпадают (рис. 2). Данный результат указывает на мультифотонный механизм возбуждения ФЛ, в основе которого фемтосекундная трехфотонная ионизация собственного вещества кристалла с последующим захватом примесными ионами зонных дырок и электронов. При этом с возбужденного состояния происходит конкурирующий переход электрона при поглощении четвертого фотона возбуждающего лазерного импульса (вставка рис. 2).

\section{Эффективность возбуждения примесных ионов фемтосекундными лазерными импульсами и наносекундными электронными пучками}

В кристаллах, возбуждаемых сильноточными наносекундными электронными пучками при плотности тока 0.05-2.0 kA/ $\mathrm{cm}^{2}$, лавинно наводится высокая концентрация зонных электронов и дырок $\left(10^{19}-10^{21} \mathrm{~cm}^{-3}\right)$. При этом последовательные взаимодействия одной пары зонных $e$ и $h$ охватывает не менее 100 собственных узлов регулярной решетки $[8,12]$. В таком случае при возбуждении плотными наносекундными электронными пучками $\left(1 \mathrm{kA} / \mathrm{cm}^{2}, 250 \mathrm{keV}, 1 \mathrm{~ns}\right)$ кристаллов, наведенные зонные $e$ и $h$ с объемной плотностью $10^{21} \mathrm{~cm}^{-3}$, последовательно взаимодействуя практически со всеми собственными и примесными ионами решетки кристалла, обеспечивают 100\% возбуждение примесных ионов. Именно этим объясняется аномальное короткоживущее просветление примесных полос поглощения в кристаллах, подвергнутых электронной бомбардировке $[8,9]$.
Кроме того, при плотности тока электронного пучка $0.05 \mathrm{kA} / \mathrm{cm}^{2}$ наблюдается аномально высокий выход $(\eta \sim 10 \%)$ КЛ ионов $\mathrm{Ce}^{3}$ и $\mathrm{Ti}^{3+}$ при их концентрации 0.1 wt.\% в кристаллах $\mathrm{Ce}: \mathrm{YAlO}_{3} ; \mathrm{Ce}: \dot{\mathrm{Y}}_{3} \mathrm{Al}_{5} \mathrm{O}_{12}$; $\mathrm{Ce}: \mathrm{Y}_{2} \mathrm{SiO}_{5} ; \mathrm{Ce}: \mathrm{LiLuF}_{4} ; \mathrm{Ti}: \mathrm{Al}_{2} \mathrm{O}_{3} ; \mathrm{Ti}: \mathrm{BeAl}_{2} \mathrm{O}_{4} ; \mathrm{Ti}: \mathrm{YAlO}_{3}$ и др. Данные результаты прямо указывают на то, что сечение взаимодействия зонных дырок и электронов с ионами примесного $\left(\sigma_{a}\right)$ и собственного $(\sigma)$ вещества отличается более чем на два порядка: $\sigma_{a} \gg \sigma[8,9]$. Это связано с тем, что в окрестности примесных дефектов потенциал, сформированный главным образом $s$ , p-, $d$-подгруппами валентных электронных оболочек примесных ионов, нерегулярен, принцип Блоха нарушается $[8,9,13]$. В этом случае электроны и дырки эффективно передают энергию примесным дефектам, что соответствует неравенству $\sigma_{a} \gg \sigma[8,9]$.

В ходе фемтосекундного лазерного возбуждения $\mathrm{YAlO}_{3}$ кристаллов по механизму трехфотонной ионизации кристаллического вещества $(n=1.94)$ в соответствии с данными импульсной фотопроводимости (рис. 2) и правой части формулы (2), при интенсивности $60 \mathrm{MW} / \mathrm{cm}^{2}$, длительности $50 \mathrm{fs}$ и диаметре пучка $1 \mathrm{~mm}$ в дисковом филаменте протяженностью $5 \mu \mathrm{m}$, где объемная интенсивность соответствует $1.2 \mathrm{GW} / \mathrm{cm}^{-3}$, наводится концентрация зонных электронов $10^{16} \mathrm{~cm}^{-3}$. Вблизи гауссовой перетяжки объемная интенсивность соответствует $\sim 10 \mathrm{TW} / \mathrm{cm}^{-3}$, концентрация зонных электронов и дырок в филаменте диаметром $10 \mu \mathrm{m}$ достигает $10^{21} \mathrm{~cm}^{-3}$ и соответствует объемной плотности зонных носителей заряда, наводимых сильноточным наносекундным пучком электронов $\left(1 \mathrm{kA} / \mathrm{cm}^{2}, 250 \mathrm{keV}, 1 \mathrm{~ns}\right)$.

На основе представленного анализа проведено единовременное исследование ФЛ и КЛ в кристаллах $\mathrm{Y}_{3} \mathrm{Al}_{5} \mathrm{O}_{12}$ номинальной чистоты (примесей $<10^{-5} \mathrm{wt} . \%$ ) при синхронном фемтосекундном лазерном и электронном возбуждении. При этом сфокусированный фемтосекундный лазерный луч диаметром $50 \mu \mathrm{m}$ проходил по кристаллу выше $200 \mu \mathrm{m}$-слоя, возбуждаемого наносекундным электронным пучком с плотностью тока $0.25 \mathrm{kA} / \mathrm{cm}^{2}$. Электронный пучок был диафрагмирован так, что система регистрации наблюдала примерно одинаковый объем свечения КЛ и ФЛ каналов. В этой серии экспериментов система регистрации запускалась по фронту наносекундного импульса пучка электронов.

Результаты, представленные на рис. 3, хорошо согласуются с приведенным выше анализом на основе данных фотопроводимости (рис. 2) и показывают высокую эффективность электронно-дырочного механизма при трехфотонном лазерном и электронном возбуждении люминесценции примеси $\mathrm{Ce}^{3+}$ с полосой при $525 \mathrm{~nm}$ и временем затухания $\tau=60 \mathrm{~ns}$ и $\operatorname{Pr}^{3+}$ при $380 \mathrm{~nm}$ и $\tau=28 \mathrm{~ns}$ в кристаллах $\mathrm{Y}_{3} \mathrm{Al}_{5} \mathrm{O}_{12}$ (рис. 3). Таким образом, при интенсивном фемтосекундном лазерном облучении указанных кристаллов механизм возбуждения 


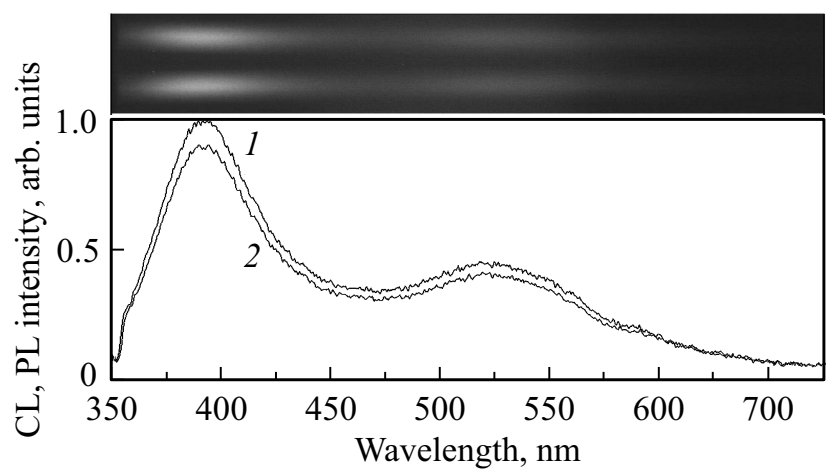

Рис. 3. Одноимпульсный спектр люминесценции $\mathrm{Ce}^{3+}$ (полоса с максимумом $525 \mathrm{~nm}$ ) и $\operatorname{Pr}^{3+}$ (полоса с максимумом $380 \mathrm{~nm}$ ) в кристаллах $\mathrm{Y}_{3} \mathrm{Al}_{5} \mathrm{O}_{12}$ при единовременном возбуждении плотным наносекундным электронным пучком (1) и фемтосекундными лазерными импульсами, $\lambda=450 \mathrm{~nm}$ (2). Регистрация: задержка $5 \mathrm{~ns}$, экспозиция $125 \mathrm{~ns}$. Сверху спектрограмма. Температура $300 \mathrm{~K}$.

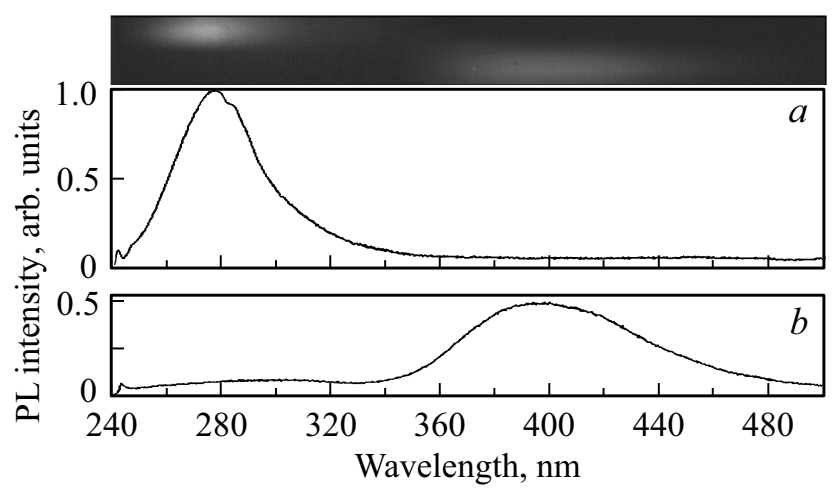

Рис. 4. Одноимпульсный единовременный спектр ФЛ $\mathrm{Ce}^{3+}$ в кристаллах $\mathrm{Ce}: \mathrm{LaF}_{3}(a)$ и $\mathrm{Ce}: \mathrm{YAlO}_{3}(b)$ при $300 \mathrm{~K}$. Возбуждение: $2 \omega: \mathrm{Ti}: \mathrm{Sp}$ лазера, $\lambda=360 \mathrm{~nm}$. Сверху спектрограмма. Регистрация: задержка $5 \mathrm{~ns}$, экспозиция $100 \mathrm{~ns}$.

примеси $\mathrm{Ce}^{3+}$ и $\mathrm{Pr}^{3+}$ соответствует реакции

$$
\begin{gathered}
3 h v \rightarrow R\left(\mathrm{O}^{2-}\right) \rightarrow e+h, \\
\left\langle\begin{array}{c}
\mathrm{Pr}^{3+}+h \rightarrow \mathrm{Pr}^{4+}+e \rightarrow\left(\mathrm{Pr}^{3+}\right)^{*} \rightarrow \mathrm{Pr}^{3+}+h v_{\mathrm{Pr}^{3+}} \\
\mathrm{Ce}^{3+}+h \rightarrow \mathrm{Ce}^{4+}+e \rightarrow\left(\mathrm{Ce}^{3+}\right)^{*} \rightarrow \mathrm{Ce}^{3+}+h v_{\mathrm{Ce}^{3+}}
\end{array}\right\rangle
\end{gathered}
$$

Единовременное наблюдение ФЛ и КЛ примесей в номинально чистых кристаллах $\mathrm{Y}_{3} \mathrm{Al}_{5} \mathrm{O}_{12}, \mathrm{YAlO}_{3}, \mathrm{Y}_{2} \mathrm{SiO}_{5}$, $\mathrm{YLiF}_{4}, \mathrm{NaCl}$, CsI (примесей $<10^{-4}$ wt.\%) и высокой частоты кристаллах $\mathrm{Al}_{2} \mathrm{O}_{3}$ (примесей $<10^{-6}$ wt.\%) при синхронном фемтосекундном лазерном $\left(\lambda_{\mathrm{exc}}=360 \mathrm{~nm}\right.$, диаметр пучка $10 \mu \mathrm{m})$ и электронном наносекундном $\left(0.25 \mathrm{kA} / \mathrm{cm}^{2}\right)$ возбуждениях зарегистрирован близкий по величине выход ФЛ и КЛ. Таким образом, при фемтосекундной многофотонной ионизации собственного вещества кристаллов возбуждение примесного состава происходит по механизму последовательного захвата примесными ионами зонных дырок и электронов.
Выше отмечено, что при электронном облучении кристаллов эффективность возбуждения примесей будет низкой при незначительном различии $s-, p$-, $d$-подгрупп внешней электронной оболочки активатора и собственных катионов решетки кристалла. Такими кристаллами являются $\mathrm{Ce}: \mathrm{LaF}_{3}\left(\mathrm{La}^{3+}-5 p^{6}, \mathrm{Ce}^{3+}-5 p^{6}\right)$. Действительно выход КЛ $\mathrm{Ce}^{3+}(5 d-4 f: 285 \mathrm{~nm}, 20 \mathrm{~ns}, 300 \mathrm{~K})$ в кристаллах $\mathrm{Ce}: \mathrm{LaF}_{3}$, соотносится с их концентрацией $\left(\mathrm{Ce}^{3+} 0.1 \mathrm{wt} . \%\right)$ и на два порядка ниже эффективности КЛ $\mathrm{Ce}^{3+}-(5 d-4 f: 360 \mathrm{~nm}, 35 \mathrm{~ns}, 300 \mathrm{~K})$ в $\mathrm{Ce}: \mathrm{YAlO}_{3}$ $\left(\mathrm{Ce}^{3+}-5 p^{6}, \mathrm{Y}^{3+}-4 p^{6}\right)$ с такой же концентрацией $\mathrm{Ce}^{3+}$ 0.1 wt. $\%$ [9].

В соответствии с данной закономерностью исследована единовременная одноимпульсная ФЛ $\mathrm{Ce}^{3+}$ при фемтосекундном лазерном возбуждении сборки из двух кристаллов $\mathrm{Ce}: \mathrm{LaF}_{3}$ и $\mathrm{Ce}: \mathrm{YAlO}_{3}$. В кристалле $\mathrm{Ce}: \mathrm{LaF}_{3}$ концентрация $\mathrm{Ce}^{3+}$ соответствовала 0.1 wt.\%, а в $\mathrm{Ce}: \dot{\mathrm{Y}} \mathrm{AlO}_{3}$ концентрация $\mathrm{Ce}^{3+}$ на два порядка меньше 0.001 wt.\%. При этом лазерный пучок был разделен на два одинаковых по интенсивности $\left(50 \mathrm{MW} / \mathrm{cm}^{2}\right)$ возбуждающих луча.

Результаты, представленные на рис. 4, показывают незначительное различие интенсивности ФЛ $\mathrm{Ce}^{3+}$ в кристаллах $\mathrm{Ce}: \mathrm{LaF}_{3}$ и $\mathrm{Ce}: \mathrm{YAlO}_{3}$ и свидетельствуют о том, что эффективность возбуждения ФЛ $\mathrm{Ce}^{3+}$ в $\mathrm{Ce}: \mathrm{YAlO}_{3}$ на два порядка выше, чем в $\mathrm{Ce}: \mathrm{LaF}_{3}$. Поэтому с учетом результатов, представленных в $[8,9]$, можно утверждать, что при фемтосекундной лазерной мультифотонной ионизации кристаллического вещества эффективность электронно-дырочного возбуждения примесного состава в кристаллах, как и при воздействии электронным пучком, определяется степенью различия электронных систем $s$-, $p$-, $d$-подгрупп внешней оболочки катионов собственного вещества и активатора и выход примесной ФЛ соответствует выражению

$$
\eta=\frac{N_{a}}{N-N_{a}} \frac{\sigma_{a}}{\sigma} \approx \frac{N_{a}}{N} \frac{\sigma_{a}}{\sigma}
$$

где $N$ - концентрация узлов кристаллической решетки.

Таким образом, в ходе интенсивного фемтосекундного лазерного возбуждения кристаллов в результате трехфотонной ионизации кристаллического вещества в электронно-дырочном филаменте концентрация зонных носителей заряда достигает $10^{21} \mathrm{~cm}^{-3}$ и соответствует объемной плотности зонных дырок и электронов, наводимых сильноточным наносекундным пучком электронов. При этом в результате трехфотонной ионизации кристаллического вещества эффективность электроннодырочного возбуждения примесного состава в кристаллах, как и при воздействии электронным пучком, определяется степенью различия электронных систем $s$-, $p$-, $d$-подгрупп внешней оболочки катионов собственного вещества и активатора. 


\section{Список литературы}

[1] Барышников В.И., Колесникова Т.А. // Опт. и спектр. 2003. T. 95. № 4. C. 638; Baryshnikov V.I., Kolesnikova T.A. // Opt. Spectrosc. 2003. V. 95. N 4. P. 638.

[2] Перлин Е.Ю., Елисеев К.А., Идрисов Э.Г., Халилов Я.Т. // Опт. и спектр. 2012. Т. 112. № 6. С. 920; Perlin E.Y., Eliseev K.A. Idrisov E.G., Xalilov Y.T. // Opt. Spectrosc. 2012. V. 112. N 6. P. 920.

[3] Барышников В.И., Колесникова Т.А. // ФТТ. 2005. Т. 47. № 10. C. 1776.

[4] Иванов А.В., Перлин Е.Ю. // Опт. и спектр. 2009. Т. 106. № 5. C. 764; Ivanov A.V., Perlin E.Y. // Opt. Spectrosc. 2009. V. 106. N 5. P. 764.

[5] Knox W.H. // IEEE J. Quant. Electron. 1986. V. 24. P. 388.

[6] Чекалин С.В. // УФН. 2006. Т. 176. Р. 657.

[7] Барышников В.И., Горева О.В. Патент РФ № 2650093, 2018.

[8] Барышников В.И., Колесникова Т.А. // ФТТ. 1998. Т. 40. № 6. C. 1030.

[9] Барышников В.И., Колесникова Т.А., Квапил И. // ФТТ. 1994. Т. 36. № 9. С. 2788.

[10] Вайсбурд Д.И., Семин Б.И., Таванов Э.Г., Матлис С.В., Балычев И.Н., Геринг Г.И. Высокоэнергетическая электроника твердого тела. Новосибирск: Наука, 1982. 225 с.

[11] Барышников В.И., Щепина Л.И., Колесникова Т.А. Патент РФ № 1795738, 1993.

[12] Алукер Э.Д., Лусис Д.Ю., Чернов С.А. Электронные возбуждения и радиолюминесценция щелочно-галоидных кристаллов. Рига: Зинатне, 1979. 252 с.

[13] Ильинский Ю.А., Келдыш Л.В. Взаимодействие электромагнитного излучения с веществом. М.: МГУ, 1989. 300 с. 